\title{
Absence-to-bilateral-tonic-clonic seizure
}

\section{A generalized seizure type}

Sándor Beniczky, MD, PhD, Guido Rubboli, MD, Athanasios Covanis, MD, and Michael R. Sperling, MD

Neurology ${ }^{\circledR}$ 2020;95:e2009-e2015. doi:10.1212/WNL.0000000000010470

\section{Abstract}

\section{Objective}

To test the hypothesis that absence seizures can evolve to generalized tonic-clonic seizures, we documented electroclinical features of this novel seizure type.

\section{Methods}

In 4 large video-EEG databases, we identified recordings of seizures starting with impaired awareness that, without returning to baseline interictal state, evolved to generalized tonic-clonic seizures. We extracted the detailed semiologic and electrographic characteristics of these seizures, and we documented the clinical background, diagnoses, and therapeutic responses in these patients.

\section{Results}

We identified 12 seizures from 12 patients. All seizures started with a period of impaired awareness and bursts of generalized spike or polyspike and slow-wave discharges, the hallmark of absence seizures. Without returning to baseline, the nonmotor (absence) phase was followed by tonic-clonic convulsions. We called this novel generalized seizure type absence-to-bilateraltonic-clonic seizure. Most patients had idiopathic generalized epilepsies, although with a high incidence of unusual features and poor therapeutic response.

\section{Conclusions}

Absence-to-bilateral-tonic-clonic seizures are a novel generalized seizure type. Clinicians should be aware of this seizure for correctly diagnosing patients. This novel seizure type may further elucidate generalized ictogenesis.

\author{
Correspondence \\ Dr. Beniczky \\ sbz@filadelfia.dk
}

MORE ONLINE

- Video

From the Department of Clinical Neurophysiology (S.B.), Danish Epilepsy Centre, Dianalund; Department of Clinical Medicine (S.B.), Aarhus University and Department of Clinical Neurophysiology, Aarhus University Hospital; Department of Neurology (G.R.), Danish Epilepsy Centre, Dianalund; University of Copenhagen (G.R.), Denmark; Neurology Unit (G.R.), IRCCS Institute of Neurological Science, Bellaria Hospital, Bologna; Italy; Department of Child Neurology (A.C.), the Children's Hospital “Agia Sophia," Athens, Greece; and Jefferson Comprehensive Epilepsy Center (M.R.S.), Department of Neurology, Thomas Jefferson University, Philadelphia, PA.

Go to Neurology.org/N for full disclosures. Funding information and disclosures deemed relevant by the authors, if any, are provided at the end of the article. 


\section{Glossary}

ABTC = absence-to-bilateral-tonic-clonic; AVI = Audio Video Interleave; EDF = European Data Format; GTCS = generalized tonic-clonic seizures; IGE = idiopathic/genetic generalized epilepsy.

Identifying seizure types in patients with epilepsy is an important step in diagnosis and is necessary for choosing the appropriate therapy. ${ }^{1}$ Identifying the clinical phenomena during seizures (semiology) and the EEG abnormalities contributes to identifying the various seizure types and may contribute to the diagnosis of epilepsy syndrome. In the recently published position paper on seizure classification, the International League Against Epilepsy recognized 4 new generalized seizure types: absence with eyelid myoclonia, myoclonic absence, myoclonic-atonic seizures, and myoclonic-tonic-clonic seizures. ${ }^{2}$ Video-EEG monitoring is needed to document the electroclinical features of these seizures. However, this resource-demanding method is used mainly in patients with drug-resistant focal epilepsy. ${ }^{3}$ Therefore, detailed documentation of those generalized seizures types that occur less frequently is challenging, leaving the possibility that some seizure types remain unrecognized.

We noticed that many patients with generalized epilepsies described a sense of confusion preceding tonic-clonic seizures. This was in agreement with the experience of several epilepsy experts who mentioned in review articles and textbook chapters absence seizures or absence status epilepticus heralding generalized tonic-clonic seizures (GTCS). ${ }^{4-6}$ However, none of these provided video or EEG documentation of the seizures. Only 1 case report provided EEG documentation (without video) of a "petit mal seizure" with immediate transition to a "grand mal seizure." We hypothesized that the initial confusion reported by patients was an integral part of the seizure rather than a simple prodrome. To investigate this hypothesis and to provide evidence for this seizure type that has previously been observed ${ }^{4-7}$ but not systematically documented in a cohort of patients, we identified seizures starting with confusion and continuing with GTCS in video-EEG databases of 4 epilepsy centers.

Although this peculiar seizure type has previously been described, ${ }^{4-7}$ here we provide detailed electroclinical documentation of absence seizures evolving to tonic-clonic seizures in a cohort of patients. We called this generalized seizure type absence-to-bilateral-tonic-clonic (ABTC) seizure. Besides the diagnostic implication, this novel seizure type contributes to a better understanding of generalized ictogenesis.

\section{Methods}

\section{Standard protocol approvals, registrations, and patient consents}

This noninterventional study was reviewed by and obtained clearance from the ethics committees of the participating centers. Patients gave written informed consent for the retrospective use of the deidentified dataset, including postprocessed video-EEG recordings with blurred faces.

\section{Patients and recordings}

We extracted cases from the video-EEG databases of 4 large epilepsy centers (Danish Epilepsy Center, Dianalund; Bellaria Hospital, Bologna; Children's Hospital Agia Sophia, Athens; Jefferson Comprehensive Epilepsy Center, Philadelphia). Inclusion criteria were seizures beginning with a period of impaired awareness evolving directly to a generalized tonicclonic seizure (formerly known as primary $\mathrm{GTCS}^{8}$ ) without return to baseline (interictal) state between the impairment of awareness and the convulsive behavior. Impaired awareness was defined as video-documented semiology features consisting of motor arrest, lack of responsiveness, or confusion, with an ictal EEG correlate for at least 5 seconds, corresponding to generalized nonmotor (absence) seizure. ${ }^{8,9}$ There were no exclusion criteria. In the video-EEG databases, we searched first for the key word "absence." This resulted in 106 patients. Then we screened the recordings for the occurrence of GTCS. In addition, we added cases remembered by the authors.

For each patient, we extracted the following data: age, sex, family history, development, cognitive and neurologic status, age at onset, reported seizure types, neuroimaging, medication, current seizure frequency, and diagnosis. Descriptive statistics were performed with Statistica software, version 13 (TIBCO, Inc, Palo Alto, CA).

\section{Electroclinical features}

All patients underwent video-EEG monitoring. EEG was recorded with standard 10-20 system electrodes ${ }^{10}$ or the extended standard array of the International Federation of Clinical Neurophysiology. ${ }^{11}$ Video-recordings were synchronized with the EEG. For each included seizure, we extracted the semiologic features ${ }^{12}$ and the EEG features ${ }^{13}$ that occurred during the ictal and postictal periods.

\section{Data availability}

Individual deidentified EEG recordings in European Data Format (EDF), video files (Audio Video Interleave [AVI] format), and self-extracting video-EEG files that include the reader (EXE format, available only for Microsoft Windows operation system) will be shared after publication. Unrestricted access to these data will be made available from the day of the online publication of the article until 2030 through a publicly accessible repository (doi.org/10.5061/dryad. tht76hdvj). The whole dataset can be downloaded using this link: doi.org/10.5061/dryad.tht76hdvj. 
Table Demographic and clinical data

\begin{tabular}{|c|c|c|c|c|c|c|c|c|}
\hline $\begin{array}{l}\text { Patient } \\
\text { nr. }\end{array}$ & $\begin{array}{l}\text { Age } \\
\text { (y), } \\
\text { gender }\end{array}$ & $\begin{array}{l}\text { Family } \\
\text { history }\end{array}$ & $\begin{array}{l}\text { Development } \\
\text { cognition and } \\
\text { neurologic } \\
\text { examination }\end{array}$ & $\begin{array}{l}\text { Age at onset and } \\
\text { seizure types }\end{array}$ & EEG & Neuroimaging & $\begin{array}{l}\text { Medication and } \\
\text { current seizure } \\
\text { frequency }\end{array}$ & Diagnosis \\
\hline 1 & $21, F$ & $\begin{array}{l}\text { Younger } \\
\text { sister had } \\
\text { febrile } \\
\text { seizures }\end{array}$ & Normal & $\begin{array}{l}12 \mathrm{y}: \text { AS and GTCS } \\
\text { while playing } \\
\text { computer game }\end{array}$ & $\begin{array}{l}\text { 3-Hz GSWD, } \\
\text { accentuated } \\
\text { during sleep }\end{array}$ & ND & LVT; seizure-free & JAE \\
\hline 2 & $48, M$ & Negative & $\begin{array}{l}\text { Head trauma at } \\
18 \mathrm{y} ; \text { normal } \\
\text { cognition and } \\
\text { examination }\end{array}$ & $20 \mathrm{y}: \mathrm{AS}$ and GTCS & $\begin{array}{l}\text { Irregular GS/ } \\
\text { PWD, } \\
\text { accentuated } \\
\text { during sleep }\end{array}$ & $\begin{array}{l}\text { MRI: bifrontal } \\
\text { contusions }\end{array}$ & $\begin{array}{l}\text { VPA and LTG; no } \\
\text { GTCS since 2013; } \\
\text { 2-3 AS/wk }\end{array}$ & $\begin{array}{l}\text { Uncertain; } \\
\text { posttraumatic } \\
\text { focal epilepsy, } \\
\text { JAE, or both }\end{array}$ \\
\hline 3 & $25, F$ & Negative & $\begin{array}{l}\text { Developmental } \\
\text { delay }(I Q \approx 65)\end{array}$ & 2 y: AS; 7 y: GTCS & GPSWD & Normal & VPA; seizure-free & $\begin{array}{l}\text { Uncertain; } \\
\text { presumed } \\
\text { genetic }\end{array}$ \\
\hline 4 & $56, M$ & Negative & Normal & $\begin{array}{l}16 \text { y: AS; } 20 \text { y: } \\
\text { GTCS. } \\
\text { Since } 41 \text { y, } \\
\text { absence status } \\
\text { terminated with } \\
\text { GTCS (twice) }\end{array}$ & GS/PWD & $\begin{array}{l}\text { Normal CT and } \\
\text { MRI }\end{array}$ & $\begin{array}{l}\text { Phenytoin and PB; } \\
\text { sporadic absences; } \\
2 \text { GTCS/y }\end{array}$ & JAE \\
\hline 5 & $55, M$ & Negative & $\begin{array}{l}\text { Mild cognitive } \\
\text { impairment } \\
\text { (slowing); } \\
\text { otherwise } \\
\text { normal }\end{array}$ & $\begin{array}{l}17 \text { y: AS; } 27 \text { y: } \\
\text { GTCS; } 55 \text { y: } 1 \\
\text { absence status } \\
\text { terminating with } \\
\text { GTCS }\end{array}$ & GS/PWD & $\begin{array}{l}\text { Normal CT and } \\
\text { MRI }\end{array}$ & $\begin{array}{l}\text { VPA and PB; daily } \\
\text { AS; } 4 \text { GTCS/y }\end{array}$ & JAE \\
\hline 6 & $17, \mathrm{M}$ & Negative & Normal & $13 \mathrm{y}:$ AS and GTCS & $\begin{array}{l}\text { 3-Hz GS/ } \\
\text { PWD }\end{array}$ & Normal MRI & $\begin{array}{l}\text { LTG and LVT; no } \\
\text { GTCS; rarely AS } \\
\text { (when forgets to } \\
\text { take medication) }\end{array}$ & JAE \\
\hline 7 & $12, F$ & $\begin{array}{l}\text { Unknown } \\
\text { (adopted) }\end{array}$ & Normal & $11 \mathrm{y}:$ AS and GTCS & 3-Hz GSWD & Normal MRI & LTG; seizure-free & JAE \\
\hline 8 & $45, F$ & Uncertain & Normal & $\begin{array}{l}\text { AS: uncertain age } \\
\text { at onset; } 37 \mathrm{y} \text { : } \\
\text { GTCS }\end{array}$ & $\begin{array}{l}\text { 3-Hz GS/ } \\
\text { PWD }\end{array}$ & Normal MRI & $\begin{array}{l}\text { VPA; 2-3 GTCS/y; } \\
\text { several AS/wk }\end{array}$ & JAE \\
\hline 9 & $18, \mathrm{M}$ & Negative & Normal & $6 \mathrm{y}: \mathrm{AS}$ and GTCS & $\begin{array}{l}\text { 3-Hz GS/ } \\
\text { PWD }\end{array}$ & Normal MRI & $\begin{array}{l}\text { VPA and LTG; 3-4 } \\
\text { AS/wk; } 1 \text { GTCS/mo }\end{array}$ & JAE \\
\hline 10 & $53, F$ & $\begin{array}{l}\text { Younger } \\
\text { brother, } \\
\text { mother, } \\
\text { and } \\
\text { maternal } \\
\text { uncle } \\
\text { have } \\
\text { epilepsy }\end{array}$ & Normal & $\begin{array}{l}12 \text { y: GTCS, } \\
\text { myoclonic jerks; } \\
15 \text { y: AS }\end{array}$ & GSWD & $\begin{array}{l}\text { MRI showed a } \\
\text { very small } \\
\text { nodular } \\
\text { heterotopia, } \\
\text { left lateral } \\
\text { ventricle } \\
\text { (frontal) } 4 \mathrm{~mm}\end{array}$ & $\begin{array}{l}\text { PB, BRV, TPM (she } \\
\text { has tried also LTG, } \\
\text { VPA, ZNS, LVT); 4-7 } \\
\text { GTCS/mo; 5-6 AS/y } \\
\text { (probably } \\
\text { underestimated); } \\
\text { 2-3 myoclonic jerks/ } \\
\text { mo }\end{array}$ & JME \\
\hline 11 & $23, \mathrm{M}$ & Negative & Normal & $\begin{array}{l}17 \mathrm{y} \text { : GTCS (in the } \\
\text { morning); brief } \\
\text { period of } \\
\text { unresponsiveness } \\
\text { preceding the } \\
\text { GTCS }\end{array}$ & $\begin{array}{l}\text { 3-Hz GS/ } \\
\text { PWD }\end{array}$ & Normal MRI & $\begin{array}{l}\text { LTG; } 1 \text { GTCS/y (poor } \\
\text { compliance) }\end{array}$ & $\begin{array}{l}\text { IGE with GTCS } \\
\text { only }\end{array}$ \\
\hline 12 & $19, \mathrm{~F}$ & Negative & $\begin{array}{l}\text { Infantile } \\
\text { autism; } \\
\text { otherwise } \\
\text { normal }\end{array}$ & $\begin{array}{l}13 \text { y: GTCS in the } \\
\text { morning; AS, } \\
\text { myoclonic jerks }\end{array}$ & $\begin{array}{l}\text { 3-Hz GS/ } \\
\text { PWD }\end{array}$ & Normal MRI & $\begin{array}{l}\text { LEV and ZNS (LTG } \\
\text { did not work); rare } \\
\text { (<1/y) GTCS; no AS, } \\
\text { no myoclonic jerks }\end{array}$ & JME \\
\hline
\end{tabular}

Abbreviations: AS = absence seizure; BRV = brivaracetam; IGE = idiopathic/genetic generalized epilepsy; JAE = juvenile absence epilepsy; GPSWD = generalized polyspike-wave discharges; GS/PWD = generalized spike/polyspike and wave discharges; GSWD = generalized spike-wave discharges; GTCS = generalized tonic-clonic seizure; JME = juvenile myoclonic epilepsy; LTG = lamotrigine; LVT = levetiracetam; ND = not done; PB = phenobarbitone; TPM = topiramate; VPA= valproate; ZNS = zonisamide.

\section{Results}

We identified 12 patients (6 female) who had video-EEG documentation of a period with impaired awareness evolving to generalized tonic-clonic seizure. The table summarizes the demographic and clinical data of the patients. Their age was between 12 and 56 years (mean 32.67 years, median 24 years, SD 17 years, interquartile range $18-50$ years). Age at onset of 
seizures was between 2 and 20 years (mean 12.64 years, median 13 years, SD 5.15 years, interquartile range 11-17 years). Two patients had a family history of seizures. In all patients, the interictal EEG showed bilateral synchronous (generalized) epileptiform discharges consisting of spike-and-slow-waves or polyspike-and-slow-waves (table). MRI showed in 1 patient bifrontal posttraumatic lesions (contusion) and in 1 patient a small $(4 \mathrm{~mm})$ periventricular nodular heterotopia of uncertain significance for the patient's seizures. Neuroimaging was not done in 1 patient and was normal in all other patients.

In 1 patient, the seizure was triggered by hyperventilation (patient 1), and in 1 patient, the seizure was triggered by intermittent photic stimulation at $23 \mathrm{~Hz}$ (patient 12). In the remaining patients, seizures occurred spontaneously.

Figures 1 and 2 show examples with EEG recordings of the seizures. Video-EEG files are available on Dryad (see the Data Availability section in Methods).

All 12 seizures started with an initial period of impaired awareness. In 3 patients, this was prolonged ( 6 minutes in patient 3 and $>30$ minutes in patients 4 and 5); in the remaining patients, its duration was between 5 and 28 seconds (median 10 seconds, interquartile range $7-15$ seconds). In all patients, bursts of bilateral synchronous (generalized) epileptiform discharges were recorded during the initial period of impaired awareness: generalized spike-wave discharges in 4 patients and mixed spike and polyspike and slow-wave discharges in 8 patients. In 6 patients, the bursts were irregular, and in 6 patients, they were rhythmic $(2.5-4 \mathrm{~Hz})$. The electroclinical features of this initial phase of the seizures were similar to those of the generalized nonmotor (absence) seizures or absence status epilepticus (in the patients with prolonged initial phase). In all patients, generalized tonicclonic behavior directly followed the initial phase of impaired awareness, without return to baseline cognitive performance before convulsive movement occurred. In 5 patients (patients 6-9 and 11), forced head version was observed at the start of the tonic phase. In 7 patients (patients 1-7), the generalized spike/ polyspike and slow-wave bursts continued until the EEG became obscured by muscle artifacts (figure 1). In 5 patients (patients 8-12), a high-frequency (beta-alpha) ictal rhythm with evolution in time appeared at the beginning of the tonic phase (figure 2).

Diagnosis was uncertain in 2 patients. Ten patients were diagnosed with idiopathic/genetic generalized epilepsy (IGE): 7 with juvenile absence epilepsy, 2 with juvenile myoclonic epilepsy, and 1 with IGE with GTCS only. Five of the 10 patients diagnosed with IGE had some unusual features: 1 patient had a very small periventricular nodular heterotopia (4 mm), 1 patient had infantile autism, 1 patient had mild cognitive impairment, and 2 patients had a history of status epilepticus. Seven patients were drug resistant (6 of the 10 patients with IGE).

Three clinical patterns emerged in our cohort: absence seizures that occasionally evolved to GTCS (8 patients), absence seizures and rare absence status epilepticus terminating with GTCS ( 3 patients), and rare GTCS preceded by absences but no isolated absence seizures ( 1 patient).

\section{Discussion}

Here, we present detailed video-EEG documentation of a generalized seizure type that we call ABTC seizures. This

Figure 1 EEG recording (patient 6) showing the transition from the absence to the tonic phase of the ABTC seizure

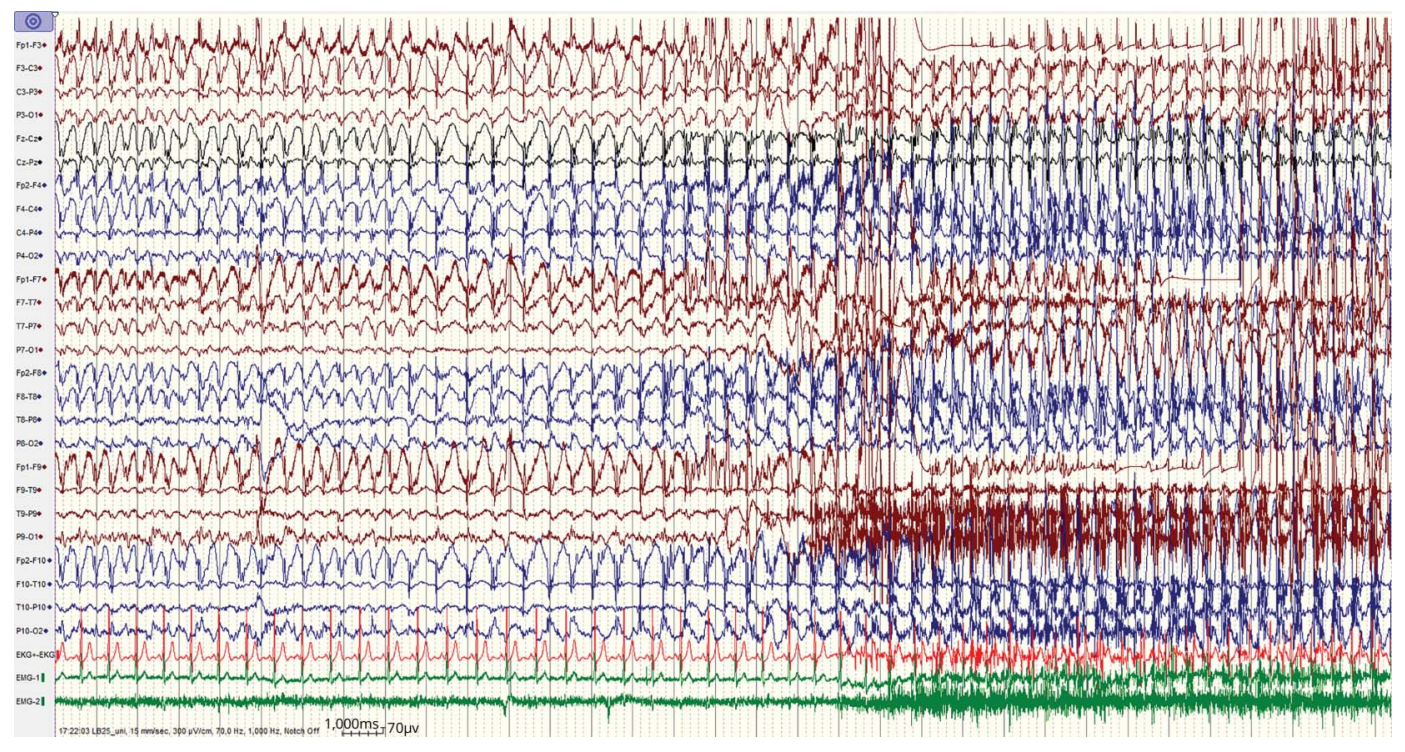

The 2 channels in green are surface EMG recorded from the left and right deltoid muscles (EMG 1/2). The generalized spike-wave bursts continue while the tonic muscle activity builds up. ABTC = absence-to-bilateral-tonic-clonic. 


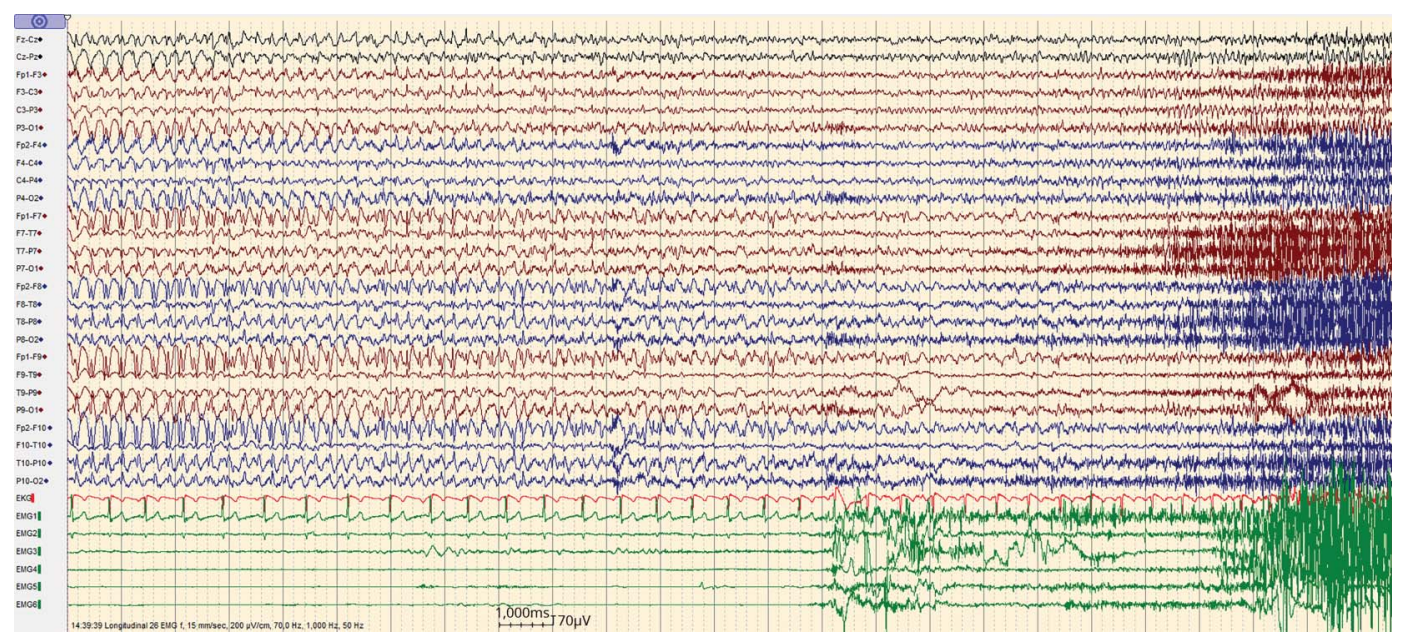

The 6 channels in green are surface EMG recorded from the left and right deltoid (EMG 1/2), brachial biceps (EMG 3/4), and anterior tibial (EMG 5/6) muscles. The generalized spike-wave bursts are gradually replaced by evolving ictal rhythm (low-amplitude fast activity). ABTC = absence-to-bilateral-tonic-clonic.

peculiar seizure has previously been described by several authors, ${ }^{4-7}$ but a systematic electroclinical documentation (video and EEG) in a cohort of patients has been lacking. The initial phase of the seizure consists of impaired awareness with the electrographic correlate of generalized bursts of spike or polyspike and slow-waves, the hallmark of generalized nonmotor (absence) seizures. ${ }^{2,5,8}$ These directly evolve to tonic and then clonic activity without an intervening baseline interictal state.

While $42 \%$ of our patients had forced head version at the beginning of the tonic phase, this does not necessary imply that these seizures are focal. A large study showed that lateralizing symptoms occurred in $52 \%$ of patients with idiopathic generalized epilepsies. ${ }^{14}$ The appearance of lateralized symptoms in a generalized seizure is in line with the concept that these seizures originate at some point within, and rapidly engaging, bilaterally distributed networks and that generalized seizures can be asymmetric. ${ }^{15}$

Although our search strategy was useful in providing goodquality video-EEG documentation of the seizures from 12 patients, it does not allow estimation of the prevalence of this seizure type for the following reasons. (1) Only patients who gave informed consent were included in the databases. (2) The referral pattern to long-term video-EEG monitoring is biased toward the more complicated patients. (3) This is not a population-based screening. Estimating the prevalence of this seizure type was beyond the goals and limitations of this study. Our aim was to collect compelling evidence from a group of patients $(n>10)$ with well-documented electroclinical features of this seizure type. Although we identified only 12 patients with ABTC seizures, it seems probable that this seizure type is more frequent because the absences preceding the tonic-clonic seizure can be very short (as little as 5 seconds), so it might go unnoticed unless seizures are recorded with video-EEG. Because patients with IGE usually respond well to therapy and are rarely evaluated with videoEEG monitoring, it is more difficult to detect this seizure type. How often it occurs remains to be determined.

Most patients in our cohort were diagnosed with generalized epilepsy syndromes encompassed within the IGE spectrum. One patient (patient 11) was classified as having IGE with GTCS only, in which no other generalized seizures (myoclonic or absences) occurred. We cannot exclude that this patient might present very brief absence episodes, i.e., phantom absences, as previously reported in some adult patients with IGE, and that would include our patient in the proposed syndrome of IGE with phantom absences. ${ }^{6}$ The other patients in our cohort had full-blown absence seizures in their history, which differentiates them from the previous study in which such patients were excluded. ${ }^{6}$ Half of our patients diagnosed with IGE had some unusual clinical features, and most were not seizure-free despite adequate choice of antiseizure medication. This could indicate that some additional factors are needed for the development of ABTC seizures and that the therapeutic response is less favorable in patients who have ABTC seizures. The alternative explanation is that this seizure type is underestimated in the general population with IGE who respond well to the medication and do not undergo video-EEG monitoring. Hence, video-EEG databases are biased toward those patients who have unusual clinical features, absence status epilepticus, and inadequate therapeutic response.

Several generalized seizures consisting of combinations of other seizure types have previously been described for absence seizures (eyelid myoclonia with absences, myoclonic absence) and for tonic-clonic seizures (myoclonic-tonic- 
clonic seizure). It is important that clinicians are aware of these seizures when taking history because questions targeting these details can contribute to the identification of the seizures and help in diagnosing the epilepsies in these patients. The combination of absence and tonic-clonic seizure co-occurring in the same seizure event has not been documented by videoEEG recordings before. This seems to combine 2 seizure categories involving different neuronal substrates and cardinally opposed mechanisms. In absences, ictogenesis is due to a predominance of inhibitory activity (aggravated by GABAergic drugs), in contrast to GTCS in which an excess of excitatory activity is present. ${ }^{16}$

How might absences trigger convulsive activity, and how might it be prevented? Absence seizures reflect dysfunction of thalamocortical networks. Spike-wave bursts reflect synchronized firing of neurons in cortex and thalamus with widespread neuronal firing and synchrony. ${ }^{17}$ Recent studies in genetic absence epilepsy rats from Strasbourg suggest that seizures are sustained by a bidirectional activation of corticothalamo-cortical circuits, with cortical and reticular thalamic neurons driving a process dependent on calcium T-channel activation. ${ }^{18}$ Because the reticular cells target only thalamocortical neurons, spread of seizures must take place at the cortical level. While absences show primary cortical involvement in somatosensory cortex, activation of cortical projections beyond this somatosensory network likely accounts for the appearance of convulsive activity. Treatment approaches might best focus on preventing the initiation of absences, which are the trigger for convulsive activity.

Recognizing the generalized seizure type described here is important both for diagnostic reasons and for understanding of generalized ictogenesis. Therapeutic implications can be inferred from the mechanisms noted above. Should tonicclonic seizures prove refractory to ordinary therapy in these patients, one might consider targeting T-channel mechanisms; this approach would need to be tested to determine efficacy.

\section{Acknowledgment}

The authors express their gratitude to nurses and technicians in the participating centers who recorded the seizures.

\section{Study funding}

The study was supported by a grant from the Juhl Family Foundation (Denmark).

\section{Disclosure}

S. Beniczky reports personal fees from Brain Sentinel, Philips, Epihunter, UCB Pharma, Bial GW Pharma, and Eisai. G. Rubboli reports speaker fees from UCB Pharma. A. Covanis reports no disclosures relevant to the manuscript. M.R. Sperling reports research contracts through the university with the NIH, Defense Advanced Research Projects Agency, UCB Pharma, Eisai, Takeda, Neurelis, SK Life Sciences, Engage Therapeutics, Medtronic, Pfizer, and Xenon, as well as consulting through the university with Medtronic, consulting with NeurologyLive, and royalties from Oxford University Press. Go to Neurology.org/N for full disclosures.

\section{Publication history}

Received by Neurology December 10, 2019. Accepted in final form April 23, 2020.

Appendix Authors

\begin{tabular}{|c|c|c|}
\hline Name & Location & Contribution \\
\hline $\begin{array}{l}\text { Sándor } \\
\text { Beniczky, } \\
\text { MD }\end{array}$ & $\begin{array}{l}\text { Danish Epilepsy Centre, } \\
\text { Dianalund, Aarhus } \\
\text { University Hospital; and } \\
\text { Aarhus University, } \\
\text { Denmark }\end{array}$ & $\begin{array}{l}\text { Designed and } \\
\text { conceptualized study; } \\
\text { analyzed the data; } \\
\text { interpreted the results; and } \\
\text { drafted the manuscript }\end{array}$ \\
\hline $\begin{array}{l}\text { Guido } \\
\text { Rubboli, } \\
\text { MD }\end{array}$ & $\begin{array}{l}\text { Department of Neurology, } \\
\text { Danish Epilepsy Centre, } \\
\text { Dianalund; and University } \\
\text { of Copenhagen, Denmark }\end{array}$ & $\begin{array}{l}\text { Designed and } \\
\text { conceptualized study; } \\
\text { collected and analyzed the } \\
\text { data; interpreted the } \\
\text { results; and revised the } \\
\text { manuscript for intellectual } \\
\text { content }\end{array}$ \\
\hline
\end{tabular}

\begin{tabular}{|c|c|c|}
\hline $\begin{array}{l}\text { Athanasios } \\
\text { Covanis, } \\
\text { MD }\end{array}$ & $\begin{array}{l}\text { Department of Child } \\
\text { Neurology, the Children's } \\
\text { Hospital "Agia Sophia," } \\
\text { Athens, Greece }\end{array}$ & $\begin{array}{l}\text { Designed and } \\
\text { conceptualized study; } \\
\text { collected and analyzed the } \\
\text { data; interpreted the } \\
\text { results; and revised the } \\
\text { manuscript for intellectual } \\
\text { content }\end{array}$ \\
\hline
\end{tabular}

\begin{tabular}{|c|c|c|}
\hline $\begin{array}{l}\text { Michael R. } \\
\text { Sperling, } \\
\text { MD }\end{array}$ & $\begin{array}{l}\text { Jefferson Comprehensive } \\
\text { Epilepsy Center, } \\
\text { Department of Neurology, } \\
\text { Thomas Jefferson } \\
\text { University, Philadelphia, PA }\end{array}$ & $\begin{array}{l}\text { Designed and } \\
\text { conceptualized study; } \\
\text { collected and analyzed the } \\
\text { data; interpreted the } \\
\text { results; and revised the } \\
\text { manuscript for intellectual } \\
\text { content. }\end{array}$ \\
\hline
\end{tabular}

\section{References}

1. Glauser T, Ben-Menachem E, Bourgeois B, et al. Updated ILAE evidence review of antiepileptic drug efficacy and effectiveness as initial monotherapy for epileptic seizures and syndromes. Epilepsia 2013;54:551-563.

2. Fisher RS, Cross JH, French JA, et al. Operational classification of seizure types by the International League Against Epilepsy: position paper of the ILAE Commission for Classification and Terminology. Epilepsia 2017;58:522-530.

3. Tatum WO, Rubboli G, Kaplan PW, et al. Clinical utility of EEG in diagnosing and monitoring epilepsy in adults. Clin Neurophysiol 2018;129:1056-1082.

4. Lüders H, Lesser RP, Dinner DS, Morris HH III. Generalized epilepsies: a review. Cleve Clin Q 1984;51:205-226.

5. Panayiotopoulos CP. The Epilepsies: Seizures, Syndromes and Management. Oxfordshire: Bladon Medical Publishing; 2005.

6. Koutroumanidis M, Aggelakis K, Panayiotopoulos CP. Idiopathic epilepsy with generalized tonic-clonic seizures only versus idiopathic epilepsy with phantom absences and generalized tonic-clonic seizures: one or two syndromes? Epilepsia 2008;49:2050-2062.

7. Niedermeyer E. Immediate transition from a petit mal absence into a grand mal seizure: case report. Eur Neurol 1976;14:11-16.

8. Commission on Classification and Terminology of the International League Against Epilepsy. Proposal for revised clinical and electroencephalographic classification of epileptic seizures. Epilepsia 1981;22:489-501.

9. Beniczky S, Neufeld M, Diehl B, et al. Testing patients during seizures: a European consensus procedure developed by a joint taskforce of the ILAE-Commission on European Affairs and the European Epilepsy Monitoring Unit Association. Epilepsia 2016;57:1363-1368.

10. Klem GH, Lüders HO, Jasper HH, Elger C. The ten-twenty electrode system of the International Federation: the International Federation of Clinical Neurophysiology. Electroencephalogr Clin Neurophysiol Suppl 1999;52:3-6.

11. Seeck M, Koessler L, Bast T, et al. The standardized EEG electrode array of the IFCN. Clin Neurophysiol 2017;128:2070-2077.

12. Blume WT, Lüders HO, Mizrahi E, et al. Glossary of descriptive terminology for ictal semiology: report of the ILAE Task Force on Classification and Terminology. Epilepsia $2001 ; 42: 1212-1218$. 
13. Beniczky S, Aurlien H, Brøgger JC, et al. Standardized computer-based organized reporting of EEG: SCORE-second version. Clin Neurophysiol 2017;128:2334-2346.

14. Seneviratne U, Woo JJ, Boston RC, et al. Focal seizure symptoms in idiopathic generalized epilepsies. Neurology 2015;85:589-595.

15. Berg AT, Berkovic SF, Brodie MJ, et al. Revised terminology and concepts for organization of seizures and epilepsies: report of the ILAE Commission on Classification and Terminology, 2005-2009. Epilepsia 2010;51:676-685.
16. Manning JP, Richards DA, Bowery NG. Pharmacology of absence epilepsy. Trends Pharmacol Sci 2003;24:542-549.

17. Huguenard J. Current controversy: spikes, burst, and synchrony in generalized absence epilepsy: unresolved questions regarding thalamocortical synchrony in absence epilepsy. Epilepsy Curr 2019;19:105-111.

18. McCafferty C, David R, Venzi M, et al. Cortical drive and thalamic feed-forward inhibition control thalamic output synchrony during absence seizures. Nat Neurosci 2018;21:744-756. 


\title{
Neurology
}

\author{
Absence-to-bilateral-tonic-clonic seizure: A generalized seizure type \\ Sándor Beniczky, Guido Rubboli, Athanasios Covanis, et al. \\ Neurology 2020;95;e2009-e2015 Published Online before print August 19, 2020 \\ DOI 10.1212/WNL.0000000000010470
}

This information is current as of August 19, 2020

\section{Updated Information \& Services}

References

Subspecialty Collections

Permissions \& Licensing

Reprints including high resolution figures, can be found at: http://n.neurology.org/content/95/14/e2009.full

This article cites 17 articles, 1 of which you can access for free at: http://n.neurology.org/content/95/14/e2009.full\#ref-list-1

This article, along with others on similar topics, appears in the following collection(s):

All Epilepsy/Seizures

http://n.neurology.org/cgi/collection/all_epilepsy_seizures Epilepsy monitoring

http://n.neurology.org/cgi/collection/epilepsy_monitoring_ Epilepsy semiology

http://n.neurology.org/cgi/collection/epilepsy_semiology

Generalized seizures

http://n.neurology.org/cgi/collection/generalized_seizures

Video/ EEG use in epilepsy

http://n.neurology.org/cgi/collection/video_eeg_use_in_epilepsy

Information about reproducing this article in parts (figures,tables) or in its entirety can be found online at:

http://www.neurology.org/about/about_the_journal\#permissions

Information about ordering reprints can be found online:

http://n.neurology.org/subscribers/advertise

Neurology ${ }^{\circledR}$ is the official journal of the American Academy of Neurology. Published continuously since 1951, it is now a weekly with 48 issues per year. Copyright Copyright ( 2020 The Author(s). Published by Wolters Kluwer Health, Inc. on behalf of the American Academy of Neurology.. All rights reserved. Print ISSN: 0028-3878. Online ISSN: 1526-632X.

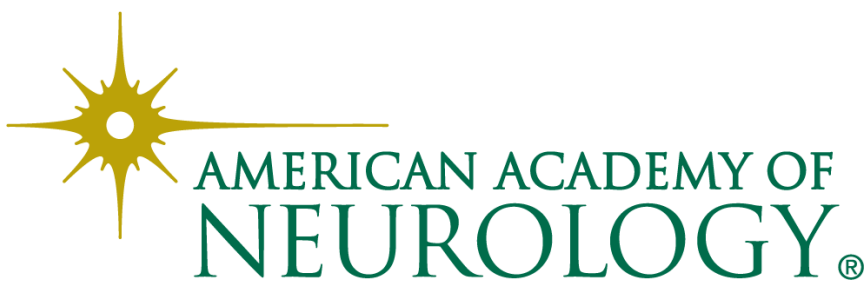

